\title{
Balloon Dissection for Extra Pleural Approach in Tracheoesophageal Fistula Repair; A Novel Technique
}

\author{
Basem Saied Abd Elqader ${ }^{1}$, Wagih Mommtaz Ghnnam² \\ ${ }^{1}$ Mansoura Children Hospital, Mansoura University, Mansoura, Egypt \\ ${ }^{2}$ Mansoura Faculty of Medicine, Mansoura University, Mansoura, Egypt \\ Email address: \\ Basemsaied2015@gmail.com (B. S. A. Elqader),wghnnam@gmail.com (W. M. Ghnnam)
}

\section{To cite this article:}

Basem Saied Abd Elqader, Wagih Mommtaz Ghnnam. Balloon Dissection for Extra Pleural Approach in Tracheoesophageal Fistula Repair; A Novel Technique.International Journal of Cardiovascular and Thoracic Surgery. Vol. 3, No. 3, 2017, pp. 14-17.

doi: $10.11648 /$ j.ijcts.20170303.11

Received: June 27, 2017; Accepted: July 4, 2017; Published: July 27, 2017

\begin{abstract}
Objective: The extra-pleural approach for the tracheoesophageal fistula is preferred by most of pediatric surgeons because the possible substantial anastomotic leak will end in a fistula rather than an empyema. The problem with this technique that it is time consuming for pleural separation and liable for pleural tears. We studied a new method for using of Foley's catheter balloon to push the pleura away from the chest wall in an easier manner and shorter time. Method: A 25 neonate with tracheoesophageal fistula was managed with the extra-pleural approach using the Foley's catheter balloon as a method of pleural separation. Results: The mean time for pleural dissection was $4.5 \mathrm{~m}(266.4 \mathrm{sec})$ with a range of $2 \mathrm{~m}, 47 \mathrm{sec}(167 \mathrm{sec})$ $6 \mathrm{~m}, 18 \mathrm{sec}(378 \mathrm{sec})$. Only 4 minor pleural tears were encountered (16\%) that passed smoothly. 4 Anastomotic leaks occurred that were managed conservatively and 2 mild Anastomotic strictures (8\%) occurred and were managed conservatively. Conclusion: Balloon dissection is a valuable addition to management of esophageal atresia. It accomplishes pleural separation from the rib cage in short time and easy manner with nearly $0 \%$ incidence of significant pleural tears. Moreover, it improves the outcome of possible postoperative anastomotic leak without adding to the patient's morbidity or the hospital cost.
\end{abstract}

Keywords: Tracheoesophageal Fistula, Surgery, Extra-pleural, Foley's Catheter

\section{Introduction}

Esophageal atresia (EA) is a congenital anomaly in which there is a blind ending upper esophagus. Moreover, the distal esophagus commonly connects to the trachea constituting a tracheoesophageal fistula (TEF) [1]. It is a relatively common congenital malformation occurring in 1:3000-4500 live births [2-4]. The etiology of this anomaly is likely to be multifactorial. The familial/syndromic cases represent less than $1 \%$ of the total whereas the overwhelming majority of cases are sporadic/non-syndromic [5]. Surgery for TEF/EA is required as early as possible to prevent aspiration and respiratory complications. Surgery is usually performed on the first or second days of life after echocardiography and evaluation of co-morbidities. The procedure involves fistula ligation and esophageal anastomosis [6]. The standard approach is a right posterolateral, muscle-sparing thoracotomy in the 4th intercostal space [2-7]. The extrapleural approach is preferred by most of pediatric surgeons because the possible substantial anastomotic leak will not be complicated by empyema but mostly ends as anesophagocutaneous fistula, which usually closes in 1-2 weeks. However, surgeons who use the trans-pleural route argue that the operative time is shorter and the risk of empyema after leak is minimal with the current antibiotics coverage [8]. For extra-pleural approach of the esophagus a tedious dissection of the pleura is almost always needed and pleural tears during such dissection are not an unusual event. Consequently, a novel method is described in this study using the balloon of a Foley's catheter to push the pleura away from the chest wall in an easier manner and shorter time.

\section{Methods}

This study included 25patients who were diagnosed as esophageal atresia with distal tracheoesopageal fistula (TEF/EA) (this type is the commonest type in our locality hence the study focused on this type).Cases were randomly selected as regard age, sex, body weight and severity of the 
associated anomalies. They were subjected to the usual screening for associated anomalies and were diagnosed by history of drooling and chocking with attempted feeding, failure to pass Ryle tube No. $10 \mathrm{~F}$, and plain X-ray chest showing the kinked Ryle tube at the upper esophagus. Preoperative preparation included routine investigations, stabilization of respiratory condition, prophylactic antibiotics, and preparation of $200 \mathrm{cc}$ packed RBCs. The standard posterolateral thoracotomy through the 4th intercostal space was used for the surgical approach (figure1). The intercostal muscles were divided and minimal dissection was performed cautiously by a wet piece of gauze to slightly separate the ribs and to create a space to introduce the catheter (figure.1). The tip of a Foley's catheter No. $10 \mathrm{~F}$ was introduced between the pleura and the ribcage with the balloon was inflated by $10 \mathrm{~cm}$ saline (figure 1,2 ). Then, the balloon was deflated and the catheter was removed and the procedure was repeated using Foley's No $12 \mathrm{~F}$ and $14 \mathrm{~F}$ inflated with 20 and $30 \mathrm{~cm}$ saline respectively until the pleura was separated from the rib cage and the Azygous vein became visible (figure 2) (we used different sizes of catheters in order not to exceed the capacity of the smaller ones by larger volumes of fluid). The operation was completed as usual and a Nelaton catheter No $18 \mathrm{~F}$ was inserted in the chest outside the pleura as a drain at the end of the operation. The time used for pleural dissection was calculated beginning just after division of the intercostal muscles till visualization of theazygous vein. Intraoperative pleural tears were recorded; those that were $2 \mathrm{~cm}$ or less were considered as minor tears and larger ones were considered as major tears. Patients were followed postoperatively by regular chest examination and plain X-ray chest after 5 days looking for postoperative pleural complications.

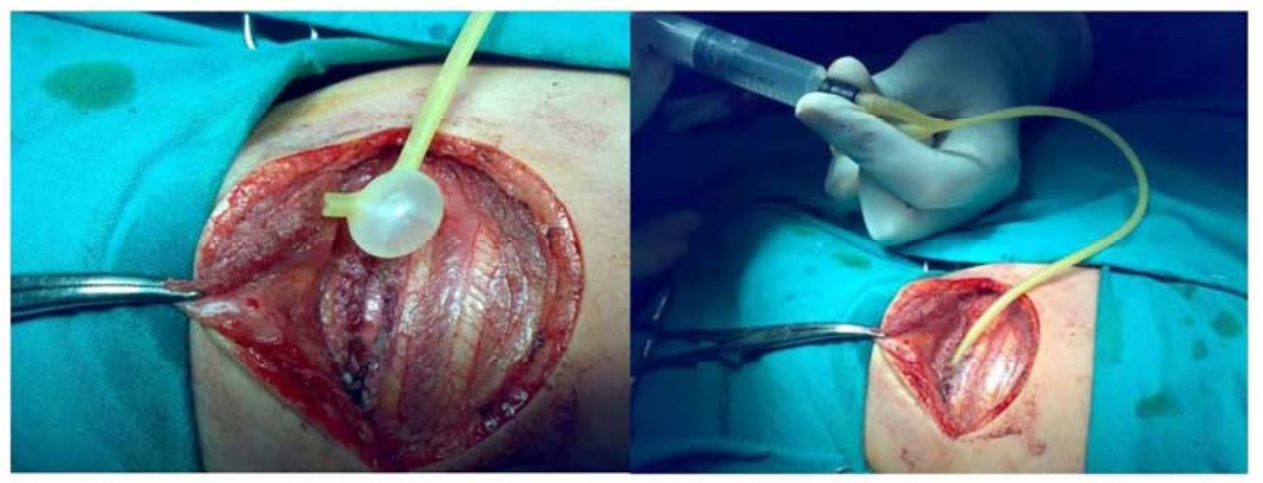

Figure 1. The tip of a Foley's catheter No. $10 \mathrm{~F}$ was introduced between the pleura and the rib cage with the balloon was inflated by $10 \mathrm{~cm}$ saline.

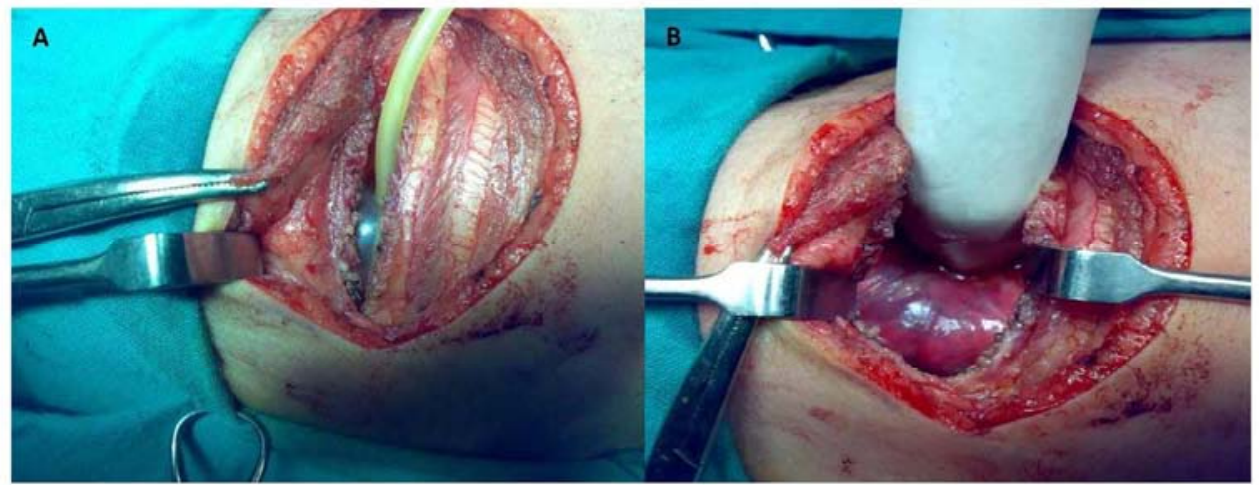

Figure 2. A) Gradual increase of the balloon size for gradual dissection of the extra-pleural space. B) Intact pleura which is completely separated from chest wall.

\section{Results}

25 patients (16 males and 9 females) with TEF/EA were included in the study. Three cases were operated at age of 2 days while one case was operated at age of 8 days (table 1 ). The rest of cases fall in between with the mean age at time of operation was 4 days. Other associated anomalies were reported in 9 cases $(36 \%)$ with cardiac anomalies being the commonest as they were reported in 5 cases $(20 \%)$ (table 1$)$. The operative time for pleural dissection, using the balloon of Foley's catheters, was calculated and the results were divided in 3 groups. Pleural dissection was accomplished within 2-4 minutes in 10 cases $(40 \%)$; on the other hand, more than 6 minutes were required for such purpose in 5 cases $(20 \%)$. The other 10 cases $(40 \%)$ required $4-6$ minutes for dissection (table 2). The shortest time required for balloon dissection of the pleura was 2 minutes and 47 seconds (167 seconds) whereas the longest time was 6 minutes and 18 seconds (378 seconds) with the mean dissection time was 4.5 minutes (266.4 seconds). A single minor pleural tear ( $2 \mathrm{~cm}$ or less) occurred during dissection in one case and was approximated by one Vicryl $5 / 0$ suture. 
In another case, 3 separate minor tears occurred in the pleura and they were left to heal spontaneously. Major pleural tears were not met in all cases. The postoperative follow up revealed no pleural complications in the form of pleural effusion, empyema or pneumothorax in any case. Anastomotic leak occurred in 4 cases (16\%). All developedesophago-cutaneous fistula that was managed conservatively and closed in 7-10 days with no signs of sepsis that mandates aggressive antibiotic regimens. Otherwise, the postoperative clinical course of all cases was smooth. Anastomotic stricture was recorded in 2 cases $(8 \%)$ that was managed successfully with dilatation.

Table 1. Patient characteristics.

\begin{tabular}{lll}
\hline & Number/ Mean & Range/ percentage \\
\hline Gender & & \\
Male & 16 & $64 \%$ \\
Female & 9 & $36 \%$ \\
Age in days & 4 & $2-8$ \\
Associated anomalies & 9 & $36 \%$ \\
\hline
\end{tabular}

Table 2. Operative outcome.

\begin{tabular}{lll}
\hline & Number/ Mean & Range/ percentage \\
\hline pleural dissection time & $4.5 \mathrm{~m}(266.4 \mathrm{sec})$ & $\begin{array}{l}2 \mathrm{~m}, 47 \mathrm{sec}(167 \mathrm{sec})- \\
6 \mathrm{~m}, 18 \mathrm{sec}(378 \mathrm{sec})\end{array}$ \\
Pleural tears & & \\
Minor & 4 & $16 \%$ \\
major & 0 & 0 \\
Anastomotic leak & 4 & $16 \%$ \\
Anastomotic stricture & 2 & $8 \%$ \\
\hline
\end{tabular}

\section{Discussion}

Esophageal atresia (EA) is the most common congenital anomaly of the esophagus. The survival of those patients improved markedly over the last two decades as a result of advances in neonatal intensive care, neonatal anesthesia, ventilatory and nutritional support, antibiotics, early surgical intervention, surgical materials and techniques [9]. Associated congenital anomalies occur in 40-60\% of infants with esophageal atresia [10-12]. Similarly, other major birth defects were reported in $36 \%$ of the included cases in this study. Cardiac anomalies were detected in $20 \%$ of cases and were found to be the commonest association. This agrees with Chittmitrappap et al., 1989 [13] who reported a 29\% co-incidence of cardiac malformations. The ideal time for primary repair is when the child becomes stable and fit for general anesthesia [14]. Hosie and Short, 2010 [1] suggested that the patient could be stabilized and surgery could be planned within the first 48 hours. In the present study the mean age at time of operation was 4 days. This is mostly because of delayed referral of cases from other centers. Extra-pleural approach is preferred nowadays by most of pediatric surgeons; however it needs a long time and tedious dissection [8]. In this study, such dissection was facilitated by using the balloon of Foley's catheter. The required time for this task ranged from 2.5 to 6 minutes with the mean time was about 4.5 minutes. So, this way of dissection obviously overcomes the drawback of lengthy traditional extra-pleural dissection. Moreover, major pleural tears during dissection were not met in any case and only minor tears were reported in 4 cases only and this didn't affect the postoperative outcome. Anastomotic leaks were reported to occur in $14-21 \%$ of patients with EA [8, 15-17]. Our 16\% incidence of anastomotic leak falls within the same range. McKinnon and Kosloske, 1990 [16] reported that the route of repair (trans-pleural or retro-pleural) didn't affect the incidence of anastomotic complications. Moreover, Bishop et al, 1985[15]; used the trans-pleural approach and reported $20 \%$ incidence of anastomotic leak. They found that the leak related mortality fallen from $88 \%$ during the period between 1951-1963 to 0\% from 1974 to 1983. This is obviously related to the development of more effective antibiotics. However, with the trans-pleural approach, the anastomotic leaks may be complicated by empyema or tension pneumothorax [8] which add to the morbidity of the patient and to the hospital cost using more aggressive antibiotic regimens. On the other hand, with extra-pleural approach and a patent mediastinal drain, up to $95 \%$ of anastomotic leaks close spontaneously [18]. In the present study, all anastomotic leaks closed smoothly without additional morbidity and with the usual antibiotics used in the postoperative care of such condition. Nowadays in the era of endoscopic surgery, the thoracoscopic approach is getting popularity [19] but in many centers with limited surgical expertise, the open technique still predominates.

\section{Conclusion}

Balloon dissection is a valuable addition to management of esophageal atresia. It accomplishes pleural separation from the ribcage in short time and easy manner with nearly $0 \%$ incidence of significant pleural tears. Moreover, it improves the outcome of possible postoperative anastomotic leak without adding to the patient's morbidity or the hospital cost.

\section{Conflict of Interest}

The authors declare that they have no conflict of interest.

\section{References}

[1] Hosie GP, Short M (2010) Oesophageal atresia. Surgery 28 (1): 38-42.

[2] Spitz L. (2007) Oesophageal atresia. Orphanet J Rare Dis. May $11 ; 2: 24$.

[3] Goyal A, Jones MO, Couriel JM, Losty PD. (2006) Oesophageal atresia and tracheo-oesophageal fistula. Archives of Disease in Childhood. Fetal and Neonatal Edition91: 381384 .

[4] De Paepe A, Dolk H, Lechat MF, EUROCAT Working Group.(1993)The epidemiology of tracheo-oesophageal fistula and oesophageal atresia in Europe. Arch Dis Child 68:743748 . 
[5] Spitz L. (2006) Esophageal atresia: Lessons I have learned in a 40-year experience. J PediatrSurg41: 1635-1640.

[6] Knottenbelt G, Skinner A, Seefelder C. (2010) Tracheooesophageal fistula and oesophageal atresia. Best Practice\& Research Clinic Anaeseth24: 387-401.

[7] Holland AJ, Fitzgerald DA. (2010) Oesophageal atresia and tracheo-oesophageal fistula current management strategies and complications. PediatrRespRev 11 (2): 100-106.

[8] Harmon CM, Coran AG. (2006) Congenital anomalies of the oesophagus. In: Grosfeld JL, O'Neill JA, Fonkalsrud EW, Coran AG, eds. Pediatric Surgery. Philadelphia: Mosby Elsevier Chapt. 67: 1051-1081.

[9] Pinheiro PF, Silva AC, Pereira RM. (2012) Current knowledge on oesophageal atresia. World J Gastroenterol 18 (28): 3662 3672 .

[10] Torfs CP, Curry CJ, Bateson TF. (1995) Population-based study of tracheoesophageal fistula and esophageal atresia. Teratology 52:220-232.

[11] Garne E, Rasmussen L, Husby S. (2002) Gastrointestinal malformations in Funen County, Denmark-epidemiology, associated malformations, surgery and mortality. Eur J PediatrSurg 12:101-106.

[12] Sparey C, Jawaheer G, Barrett AM, Robson SC. (2000) Esophageal atresia in the Northern Region Congenital Anomaly Survey, 1985-1997: prenatal diagnosis and outcome. Am J ObstetGynecol182:427-431.
[13] Chittmitrappap S, Spitz L, Kiely EM, Brereton RJ. (1989) Oesophageal atresia and associated anomalies. Arch Dis Child 64:364-368.

[14] Gupta DK, Sharma S. (2008) Esophageal atresia: the total care in a high-risk population. Seminars in PediatrSurg 17 (4): 236243.

[15] Bishop PJ, Klein MD, Philippart AI, Hixson DS, Hertzler JH. (1985) Transpleural repair of esophageal atresia without a primary gastrostomy: 240 patients treated between 1951 and 1983. JPediatrSurg 20(6): 823-828.

[16] McKinnon LJ, Kosloske AM. (1990)Prediction and prevention of anastomotic complications of esophageal atresia and tracheoesophageal fistula. J PediatrSurg 25(7): 778-781.

[17] Chittmitrappap S, Spitz L, Kiely EM, Brereton RJ. (1992) Anastmotic leakage following surgery for oesophageal atresia. J PediatrSurg 27 (1): 29-32.

[18] Manning PB, Morgan RA, Coran AG, Wesley JR, Polley TZ, Behrendt DM, Kirsh MM, Sloan HE. (1986) Fifty years' experience with oesophageal atresia and tracheo-oesophageal fistula. Beginning with Cameron Haight's first operation in 1935. Ann Surg 204: 446-453.

[19] Holcomb GW $3^{\text {rd }} 1$, Rothenberg SS, Bax KM, Martinez-Ferro M, Albanese CT, Ostlie DJ, van Der Zee DC, Yeung CK. (2005) Thoracoscopic repair of esophageal atresia and tracheoesophageal fistula: a multi-institutional analysis. Ann Surg. Sep; 242(3):422-8; discussion 428-30. 